Sādhanā Vol. 39, Part 3, June 2014, pp. 637-657. (C) Indian Academy of Sciences

\title{
Design of RC frames for pre-selected collapse mechanism and target displacement using energy-balance
}

\author{
ONUR MERTER $^{1, *}$ and TANER UCAR ${ }^{2}$ \\ ${ }^{1}$ Department of Civil Engineering, Dokuz Eylul University, Buca 35160, \\ Izmir, Turkey \\ ${ }^{2}$ Department of Architecture, Dokuz Eylul University, Buca 35160, Izmir, Turkey \\ e-mail: onur.merter@deu.edu.tr; taner.ucar@deu.edu.tr
}

MS received 18 April 2013; revised 17 July 2013; accepted 13 September 2013

\begin{abstract}
In earthquake-prone countries, structures may be exposed to several seismic loads in any stage of building's life. It is expected that the structures designed by engineers will show ductile behaviour under the effect of vertical and lateral loads and remain stable without making a sudden collapse. In consequence of nonlinear behaviour, plastic hinges are expected to form in structural members which are under the effect of external loads. Earthquake input energy is dissipated in plastic hinges, so, structures behave ductile. In this study, total energy of RC frames is calculated and the energy-based base shear force is determined by equating the total internal energy to the work done by external lateral design forces for pre-selected target displacement and collapse mechanism. Sections of RC frames are controlled if they can resist the calculated design lateral loads or not. If the capacity of the sections cannot withstand the external design loads, the design is rearranged and new sections are chosen. Beam and column sections that can resist the design loads securely are accepted as final sections of the energy-based design methodology. Pre-selected target displacement for desired performance level is checked using the results of nonlinear analyses. The results of the presented design methodology in this study are compatible with the results of nonlinear analyses.
\end{abstract}

Keywords. Plastic hinge; earthquake input energy; energy-based base shear; nonlinear static pushover analysis; nonlinear dynamic time history analysis.

\section{Introduction}

Methods for seismic design of structures are generally force-based, displacement-based and energy-based. In the force-based design methodology, seismic code-based elastic design spectrum is generally used and seismic loads are reduced in order to take into account of nonlinear behaviour of structures. As it is known, most structures behave nonlinear under earthquake excitations and thus structures have nonlinear displacements. Displacement-based methods are used

*For correspondence 
for performance assessment of structures and directly consider the nonlinear behaviour. Plastic hinges are formed in the structure that behave nonlinear and it is accepted that earthquake input energy is dissipated in these plastic regions. In the energy-based structural design methodology, earthquake excitation is considered as an energy input into the structure. It is aimed that the input energy is consumed by the nonlinear behaviour and with damping mechanism of the structure.

In an energy-based seismic design, it is important to estimate the energy input to the structures. There are many studies on literature about the seismic input energy and energy-based design and evaluation of structures. The use of energy concepts in earthquake resistant structural design becomes popular especially in last fifty years. Energy-based earthquake resistant design was first proposed by Housner (1956). Housner (1956), made estimation about the energy input to the structures with the earthquake by using the velocity spectra of the elastic systems. Energy-based design parameters and characteristics of the effective strong ground motions were defined by Housner (1956) and these studies formed a basis for earthquake resistant energybased design. Also some other researchers made many previous estimations at past about the energy input concept. Zahrah \& Hall (1984), Akiyama (1985), Kuwamura \& Galambos (1989), Fajfar et al (1989), Uang \& Bertero (1990) and Manfredi (2001) proposed analytical equations for the energy input calculation of structural systems. Akbas (1997), Akbas et al (2001, 2002, 2005) and Akbas \& Shen (1996, 2002, 2003) made several studies about earthquake resistant design and energy concepts. Subjects such as seismic energy types, energy parameters, energy concepts in performance-based design and hysteretic energy demands were widely researched by Akbas (1997) and Akbas et al (2001, 2002, 2005). Acun \& Sucuoglu $(2007,2010)$ researched structural performance assessment of RC column members with energy-based procedures in their studies. Sucuoglu \& Erberik (2004) made some studies about the energy-based hysteresis and damage models. Park \& Eom (2006) and Eom \& Park (2010) investigated the energy dissipation of slender RC members by using the cyclic stress-strain relationships of the concrete and reinforcing steel materials. In their study, the energy dissipation in RC members with the nonlinear behaviour is formulated and used to estimate the equivalent damping ratios. Leelataviwat (1998) and Leelataviwat et al $(2002,2008,2009)$ designed the structures by using yield mechanism, target drift and energy balance concept. The design base shear was calculated by writing an energy balance equation of the system considering the limit state collapse mechanism in their studies. Plastic energies were assumed to dissipate in plastic regions and target drift was chosen for the structural design. The new seismic design procedure developed by Leelataviwat (1998) was performed for the steel moment-resisting frames and target drift was compared to the drift result of the nonlinear dynamic time history analysis.

The objective of this study is to make an energy-based earthquake resistant design of RC frame structures for a pre-selected collapse mechanism and a target roof displacement. The methodology can be referred to an extension of Leelataviwat's study (Leelataviwat et al 2002) in one sense and in this research, not only the plastic energy equilibrium is written but also the total (elastic and plastic) energy equilibrium is used instead. In this study, the Turkish Seismic Design Code (TSDC 2007) is used to determine the equivalent earthquake loads. Performance levels (target displacements) of the structures used in this study are obtained by considering ATC-13 (1985) report. In literature, energy-based structural design studies are commonly performed for steel moment-resisting frames but the studies on energy-based design of RC structures are insufficient. In this study, an iterative energy-based methodology is presented for RC frames. Energy balance for frame structures with different stories is written in the limit collapse state and then energy-based base shear is obtained. Then the structural members are controlled if their sections can resist the calculated design lateral loads or not. If the capacity of the sections cannot withstand the external design loads, the design should be rearranged and new section dimensions 
and reinforcing bars should be chosen. At the end of the design, selected performance level (target displacement) is compared with the displacement results of nonlinear static (pushover) and nonlinear dynamic time history analyses. Seven strong ground motion data are chosen for nonlinear time history analyses and direct integration method is used to perform nonlinear dynamic analyses.

\section{Energy-based design methodology}

In the design methodology which uses energy the balance of collapse mechanism of RC frames, moment-curvature relationships of structural members should be initially obtained. Momentcurvature relations of RC beam and column members are required for both nonlinear analyses and energy calculations within the study. The area under the moment-curvature graph is an indicator of section ductility and total energy that can be consumed by RC sections. The energy consumption in the unit length of the RC section can be obtained by using the moment-curvature relationships (figure 1).

The total energy consumption $(E)$ in ductile RC section can be expressed by the sum of the elastic and plastic energies.

$$
E=E_{e}+E_{p}
$$

In Eq. (1) $E_{e}$ is elastic energy and $E_{p}$ is plastic energy. It is known that elastic energy is an energy type which occurs with the elastic behaviour of the section. RC section behaves nonlinear in consequence of external loads (especially lateral loads such as earthquake) and the energy type is called plastic energy in nonlinear region. In the methodology within the study, total (elastic and plastic) energy balance is used to obtain the design base shear of the structures. Pre-selected collapse mechanism and plastic regions that are assumed in the study can be seen in figure 2, where $\delta_{p}$ is the lateral plastic roof displacement, $\theta_{p}$ is the plastic base rotation and $H$ is the total height of the structure.

According to the chosen collapse (yield) mechanism of RC frame structures, it is assumed that plastic hinges will occur in the bottom region of columns and in the both ends of beams (in relative 'zero' and 'one' points). Strong column - weak beam mechanism is accepted as the main collapse mechanism within the study. Plastic rotation can be written as in Eq. (2).

$$
\theta_{p} \cong \frac{\delta_{p}}{H}
$$

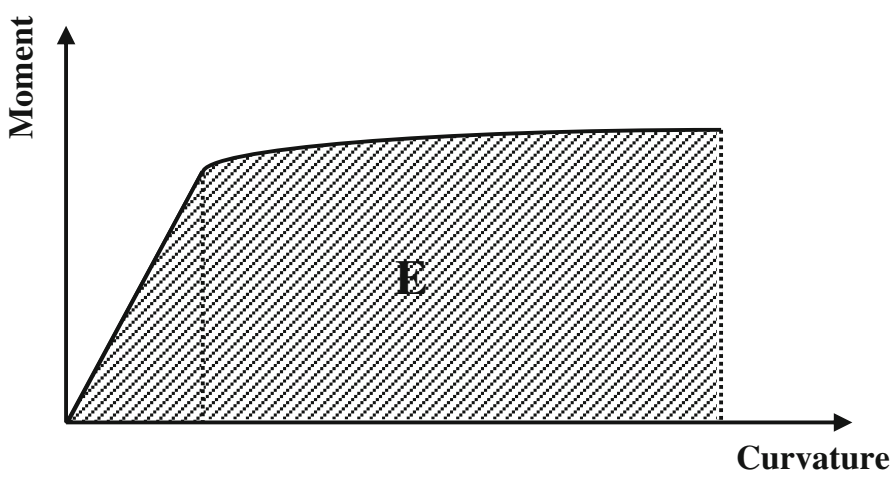

Figure 1. Moment-curvature relationship and energy consumption in unit length of ductile RC section. 


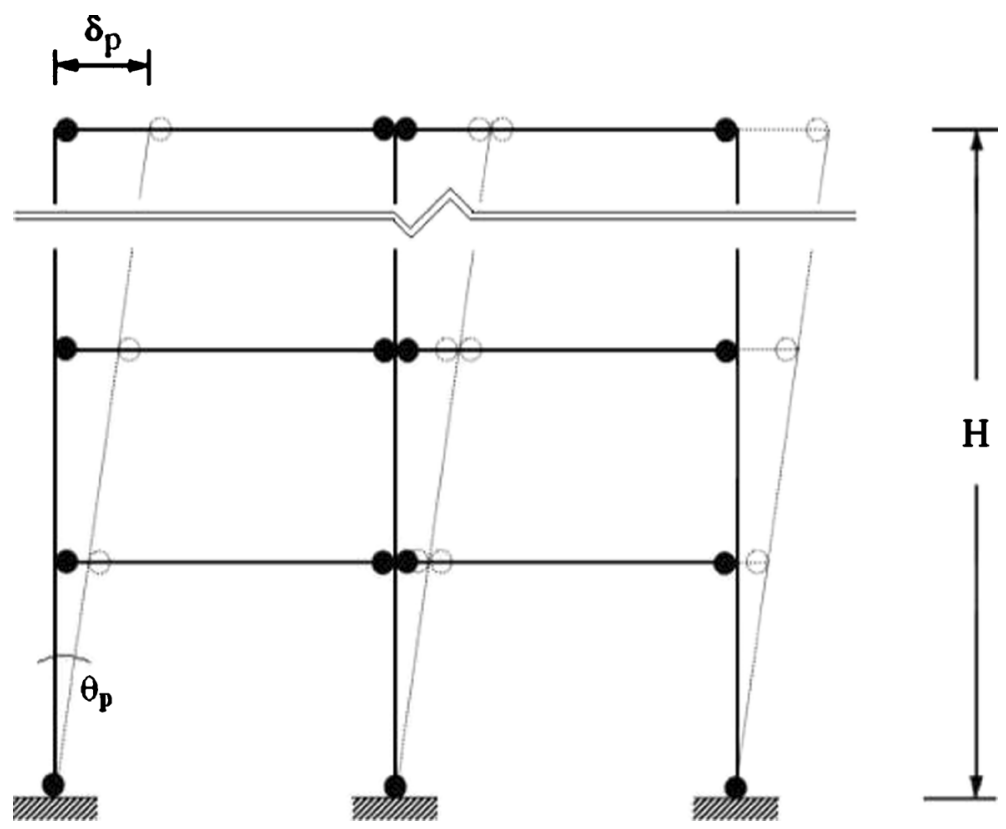

Figure 2. Pre-selected collapse mechanism and assumed plastic hinge regions.

In this study, it is assumed that the frame structure makes a plastic rotation from the base level in the value of ' $\theta_{p}$ '. In the design methodology, the total plastic energy dissipated in the plastic region of the structures according to the pre-selected collapse mechanism is determined. The total plastic energy dissipation due to nonlinear behaviour of the whole structure can be written as the sum of the plastic energies of the plastic hinges.

$$
E_{p}=\sum E_{p b}+\sum E_{p c}
$$

In Eq. (3) $E_{p b}$ is the plastic energy of plastic hinges that occur in beam members, $E_{p c}$ is the plastic energy of plastic hinges that occur in column members (at the base, figure 2) and $E_{p}$ is the total plastic energy of the frame structure. Regular RC frame structures are dealt within the study and so the total plastic energy of the beam hinges can be expressed as

$$
\sum E_{p b}=2 m n E_{p, \text { beam }}
$$

where $m$ is the beam number in one story, $n$ is the number of stories of the structure and $E_{p \text {,beam }}$ is the plastic energy dissipation value of a plastic hinge region (only one plastic hinge) that occurs in beam member. Eq. (4) is valid for structures which have the same beam dimensions and reinforcement arrangements in each story. This assumption is accepted within the study and $\mathrm{E}_{p \text {, beam }}$ can be expressed as in Eq. (5).

$$
E_{p, \text { beam }}=M_{p b} \theta_{p b}=M_{p b} \phi_{p b} L_{p b}
$$

In Eq. (5), $M_{p b}$ is the plastic moment of the beam, $\theta_{p b}$ is the design plastic rotation of the beam plastic hinge, $\phi_{p b}$ is the plastic curvature and $L_{p b}$ is the plastic hinge length. 
In phenomena of reinforced concrete design, it is accepted that plastic hinge moment is approximately equal to $M_{r b}$ which is the resistance moment of a beam (Ersoy \& Ozcebe 2001) and Eq. (5) can be revised as in Eq. (6).

$$
E_{p, \text { beam }}=M_{r b} \theta_{p b}=M_{r b} \phi_{p b} L_{p b} .
$$

RC beam sections for which the ratio of compression reinforcement $\left(A_{s}^{\prime}\right)$ to the tension reinforcement $\left(A_{s}\right)$ is in the range of 0.25 and 2, the resistance moment of the section can be approximately obtained with Eq. (7) (Ersoy 1998; Ersoy \& Ozcebe 2001). Comprehensive investigations made by Ersoy (1998) and Ersoy \& Ozcebe (2001) has revealed that the maximum possible percentage of error caused by Eq. (7) is 6\%. Due to convenience of approximate formula (Eq. 7), this error can be ignored.

$$
M_{r b} \cong A_{s} f_{y d}\left(d-d^{\prime}\right)
$$

In Eq. (7), $f_{y d}$ is the yield strength of the steel reinforcement, $d$ ' is concrete cover and $d$ is the distance from the extreme fibre in compression to the centroid of the steel on the tension side of the member (MacGregor 1997). Substituting Eq. (7) into Eq. (6), the explicit form of the plastic energy of the beam can be written as in Eq. (8). And after substituting Eq. (8) in Eq. (4) and Eq. (9), which shows the total plastic energy of plastic hinges of a beam, is obtained.

$$
\begin{gathered}
E_{p, \text { beam }} \cong A_{s} f_{y d}\left(d-d^{\prime}\right) \phi_{p b} L_{p b}, \\
\sum E_{p b} \cong 2 m n A_{s} f_{y d}\left(d-d^{\prime}\right) \phi_{p b} L_{p b} .
\end{gathered}
$$

The total plastic energy dissipation of the column bases in the presented methodology can be described by using Eq. (10):

$$
\sum E_{p c}=(m+1) E_{p, \text { column }}
$$

where $E_{p \text {,column }}$ is the plastic energy dissipation value of a plastic hinge region (only one plastic hinge) that occurs in the column member.

In the design methodology within the study, performance levels of the structures are chosen according to (ATC-13 1985) report (table 1). In the pre-selected limit (collapse) state, the interstory drifts will be equal in each story. Because of this, interstory drift ratios can be used as a design criterion. Performance Level IV (Moderate Damage State) is chosen in this study.

Table 1. Performance levels according to interstory drift ratios (ATC-13 1985).

\begin{tabular}{lcc}
\hline Performance level & Damage state & Interstory drift ratio (\%) \\
\hline I & None & $(\delta / H)<0.2$ \\
II & Slight & $0.2<(\delta / H)<0.5$ \\
III & Light & $0.5<(\delta / H)<0.7$ \\
IV & Moderate & $0.7<(\delta / H)<1.5$ \\
V & Heavy & $1.5<(\delta / H)<2.5$ \\
VI & Major & $2.5<(\delta / H)<5$ \\
VII & Destroyed & $(\delta / H)>5$ \\
\hline
\end{tabular}


The total rotation of the structures from the base $\left(\theta_{T}\right)$ at the limit collapse state can be obtained by using Eq. (11).

$$
\theta_{T} \cong \frac{\delta}{H}=\frac{\delta_{y}+\delta_{p}}{H} .
$$

In Eq. (11) $\delta_{y}$ is the yield displacement. In this study, the elastic yield rotation ' $\theta_{y}$ ' is taken as $1 \%$ considering the acceptations in literature (Leelataviwat et al 2002; Priestley et al 2007). Elastic rotation expressed by Priestley et al (2007) for regular RC frames is

$$
\theta_{y} \cong \frac{\delta_{y}}{H}=0.5 \varepsilon_{y} \frac{L_{b}}{h_{b}}
$$

where $\varepsilon_{y}$ is the yield strain, $L_{b}$ is the beam span and $h_{b}$ is the height of RC beam. Eq. (12) is accepted as the elastic yield rotation of the RC frames within the study. The total rotation of the $\mathrm{RC}$ frame from the base level can be expressed by the sum of its elastic and plastic components Eq. (13).

$$
\theta_{T}=\theta_{y}+\theta_{p}
$$

The total rotation $\left(\theta_{T}\right)$ in the presented design methodology is taken from table 1 (ATC-13 1985). Elastic rotation is calculated by using Eq. (12) (Priestley et al 2007). Then, plastic rotation can be easily obtained from Eq. (13).

In figure 3, an idealized moment-curvature relation of a ductile RC section can be seen. In this figure; $M_{p}$ is the plastic moment, $\phi_{y}$ is the elastic yield curvature, $\phi_{p}$ ' is the curvature of the section in nonlinear behaviour and $\phi_{u}$ is the ultimate curvature. Representative form of a bilinear moment-curvature relation shows the plastic energy consumption $\left(E_{p}^{\prime}\right)$ of an RC section in its unit length. In the design, the total rotation is pre-selected (table 1) and so the plastic rotation $\theta_{p}$ can be obtained. Plastic curvature of a plastic hinge $\left(\phi_{p}\right)$ can be expressed by Eq. (14) where $L_{p}$ is the length of plastic hinge region.

$$
\phi_{p}=\frac{\theta_{p}}{L_{p}} .
$$

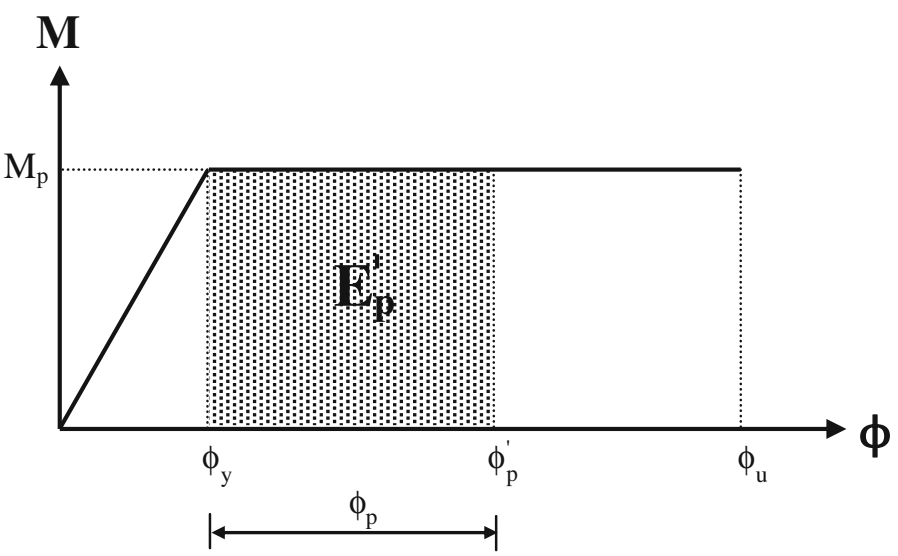

Figure 3. Bilinear moment-curvature relation and plastic energy consumption of an RC section in its unit length. 
The total plastic energy of a plastic hinge region can be rewritten as

$$
E_{p}=E_{p}^{\prime} L_{p}
$$

where $E_{p}$ corresponds to the plastic energy dissipation value of a plastic hinge region (only one plastic hinge) that occurs in a structural member. $E_{p}$ is the plastic energy value which is abbreviated as $E_{p \text {,beam }}$ in Eq. (5) for beam members or as $E_{p \text {,column }}$ in Eq. (10) for column members. $E_{p}^{\prime}$ is the plastic energy in unit length of the plastic region (figure 3 ).

\subsection{Design base shear determination}

In the energy-based design methodology within the study, it is accepted that the equivalent earthquake forces act on story levels according to the Turkish Seismic Design Code (TSDC 2007), (figure 4). The total work done by external lateral design loads are equalized to the internal energy of RC frame system and so, the design base shear force $\left(V_{T}\right)$ is obtained.

In figure $4, N$-floored moment frame with rigid diaphragms at floor levels subjected to lateral forces can be seen. $F_{1}, F_{i}$ and $F_{N}$ are the lateral design loads and $\Delta F_{N}$ is the additional earthquake load which acts on the floor N (TSDC 2007). $\delta_{1}, \delta_{i}$ and $\delta_{N}$ are the lateral displacements of corresponding story levels. $V_{T}$ is the design base shear force which is obtained by writing the energy - balance equalities. The total work done by the design loads can be expressed by Eq. (16).

$$
E=E_{e}+E_{p}=\left(\sum_{i=1}^{N} F_{i} H_{i}+\Delta F_{N} H_{N}\right) \theta_{T}
$$

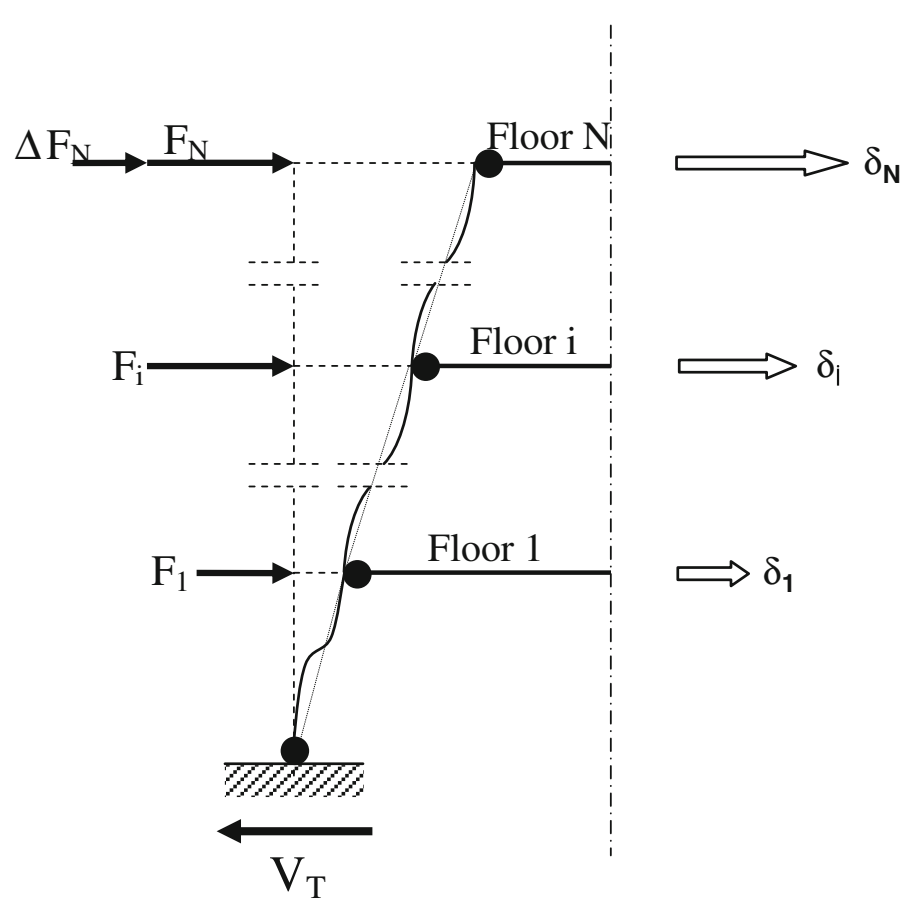

Figure 4. $N$-floored moment frame with rigid diaphragms subjected to lateral forces. 
In Eq. (16) $F_{i}$ is the equivalent earthquake load that acts on the story $i$ (figure 4 ), $H_{i}$ is the height of the story $i$ and $H_{N}$ is the height of the story $N$ (roof story). After writing the external energy equality (Eq. (16)), the internal energy of the system should be written. The internal energy of the system will be equal to the sum of the plastic energies which are consumed in the plastic hinge regions of the selected yield mechanism and elastic energies of the structural members. The plastic energy consumption of the RC frame system can be expressed by Eq. (17).

$$
E_{p}=\sum E_{p b}+\sum E_{p c} \cong 2 m n A_{s} f_{y d}\left(d-d^{\prime}\right) \phi_{p b} L_{p b}+(m+1) E_{p, \text { column }},
$$

where $A_{s}$ is the tension reinforcement of a beam member, $f_{y d}$ is the yield strength of beam reinforcement, $d$ is the distance from the extreme fibre in compression to the centroid of the steel on the tension side of the beam member, $\phi_{p b}$ is the plastic curvature, $L_{p b}$ is the plastic hinge length of a beam, $n$ is the number of stories in the structure, $m$ is the beam number in one story and $E_{p, \text { column }}$ is the plastic energy dissipation value of a plastic hinge region that occurs in a column member. $E_{p \text {,column }}$ can be calculated from nonlinear properties of column sections. For this requirement, moment-curvature relations of column members should be obtained and then plastic energies can be calculated.

Based on the energy-balance concept (figure 5), elastic energy of the frame structure $\left(E_{e}\right)$ can be estimated as follows

$$
E_{e}=\frac{1}{2} \delta_{y} V_{y}=\frac{1}{2} \frac{V_{y}^{2}}{M \omega_{n}^{2}},
$$

where $V_{y}$ is the yield or design base shear $\left(V_{y}=V_{T}\right), \delta_{y}$ is the yield displacement, $M$ is the total mass of the system and $\omega_{n}$ is the fundamental natural frequency. In figure 5 , the idealized elasto-plastic system and elastic $\left(E_{e}\right)$ and plastic $\left(E_{p}\right)$ energies of the system can be seen.

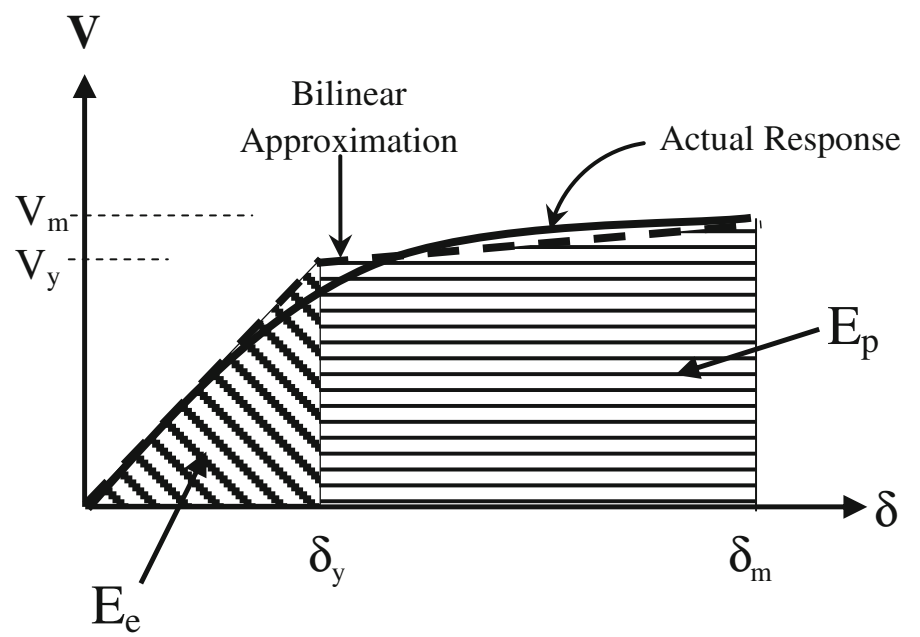

Figure 5. Actual and idealized force-displacement relationship. 
In Eq. (18), the yield displacement $\delta_{y}$ can be obtained by using Priestley's estimation for RC frame systems (Eq. (12)). The total work done by the lateral design forces (Eq. (16)) can be equalized to the sum of the elastic (Eq. (18)) and plastic energy (Eq. (17)) of the RC frame system as:

$$
\left(\sum_{i=1}^{N} F_{i} H_{i}+\Delta F_{N} H_{N}\right) \theta_{T}=E_{e}+E_{p},
$$

where $F_{i}$ is the design lateral load as given in Eq. (20) (equivalent earthquake force according to TSDC (2007)):

$$
F_{i}=\left(V_{T}-\Delta F_{N}\right) \frac{w_{i} H_{i}}{\sum_{j=1}^{N} w_{j} H_{j}} .
$$

In Eq. (20) $\Delta F_{N}$ is the additional roof level force and can be expressed as in Eq. (21) (TSDC 2007).

$$
\Delta F_{N}=0.0075 N V_{T}
$$

The concept employed in equivalent static lateral force methods is to place static loads on a structure with magnitudes and direction that closely approximate the effects of dynamic loading caused by earthquakes. Concentrated lateral forces due to dynamic loading tend to occur at floor and roof levels in structures, where concentration of mass is the highest. Furthermore, concentrated lateral forces tend to be larger at higher elevations in a structure. Thus, the greatest lateral displacements and the largest lateral forces often occur at the top level of a structure (particularly for tall buildings). These effects are modelled in equivalent static lateral force procedures of the UBC (1997) and IBC (2003) codes by placing a force at each story level in a structure (equivalent static story forces). And, the additional force $\left(\Delta F_{N}\right)$ is added to the equivalent static force that acts to the top (roof) level of a structure. In the view of such information, the TSDC (2007) uses the additional roof level force ' $\Delta F_{N}$ ' in the design with equivalent static lateral force procedure as indicated in UBC (1997) and IBC (2003) codes.

Substituting Eqs. (17), (18), (20) and (21) into Eq. (19), the energy-balance equality is explicitly obtained. From the total energy-balance of the structure, the total design base shear $\left(V_{T}\right)$ can be obtained and applied to the structure. The energy-balance concept in this study is based on the assumption that the total energy required to push the structure up to the target displacement is equal to the maximum earthquake input energy of an equivalent elastic system (Leelataviwat et al 2002).

\subsection{Iterative processes for the design methodology (energy-balance steps)}

The design methodology within the study is based on iterative calculation processes. Firstly, RC frames are designed according to the Turkish Seismic Design Code (2007) and the Requirements for Construction of Reinforced Concrete Structures (TS500 2000). Then, interstory drift ratio is targeted by using ATC-13 (1985) report (table 1) considering the usage function of the structure. Collapse (yield) mechanism of the frame is pre-selected at the beginning of the design.

The total energy-balance equation of the frame structure is written for the target displacement and pre-selected collapse mechanism. The design base shear force is obtained from the 
energy-balance equality. Then the design base shear force is applied to the structure and the structure is checked if it can resist the design lateral loads or not. If the structure cannot resist the design lateral loads, dimensions of structural members (beams and columns) or reinforcement details of sections are changed (mostly increased). After changing the dimensions of structural members or reinforcement detailing, the new frame structure is obtained. The energybalance equation is rewritten and base shear is determined again for the new structure and the new base shear force is applied to the new structure. The structure is checked again to check whether it can resist the new design lateral loads or not. If the new structure cannot resist the new design lateral loads, dimensions or reinforcement details are changed again. This process is repeated until the structure resists the design lateral loads (figure 6). Then the iterative calculation process is stopped and the base shear force at the last step is accepted as the design lateral load (result) of the methodology.

The energy-based design methodology within the study is a kind of limit analysis procedure. Although the limit (plastic) analysis procedure is not too convenient for the RC structures (Ersoy

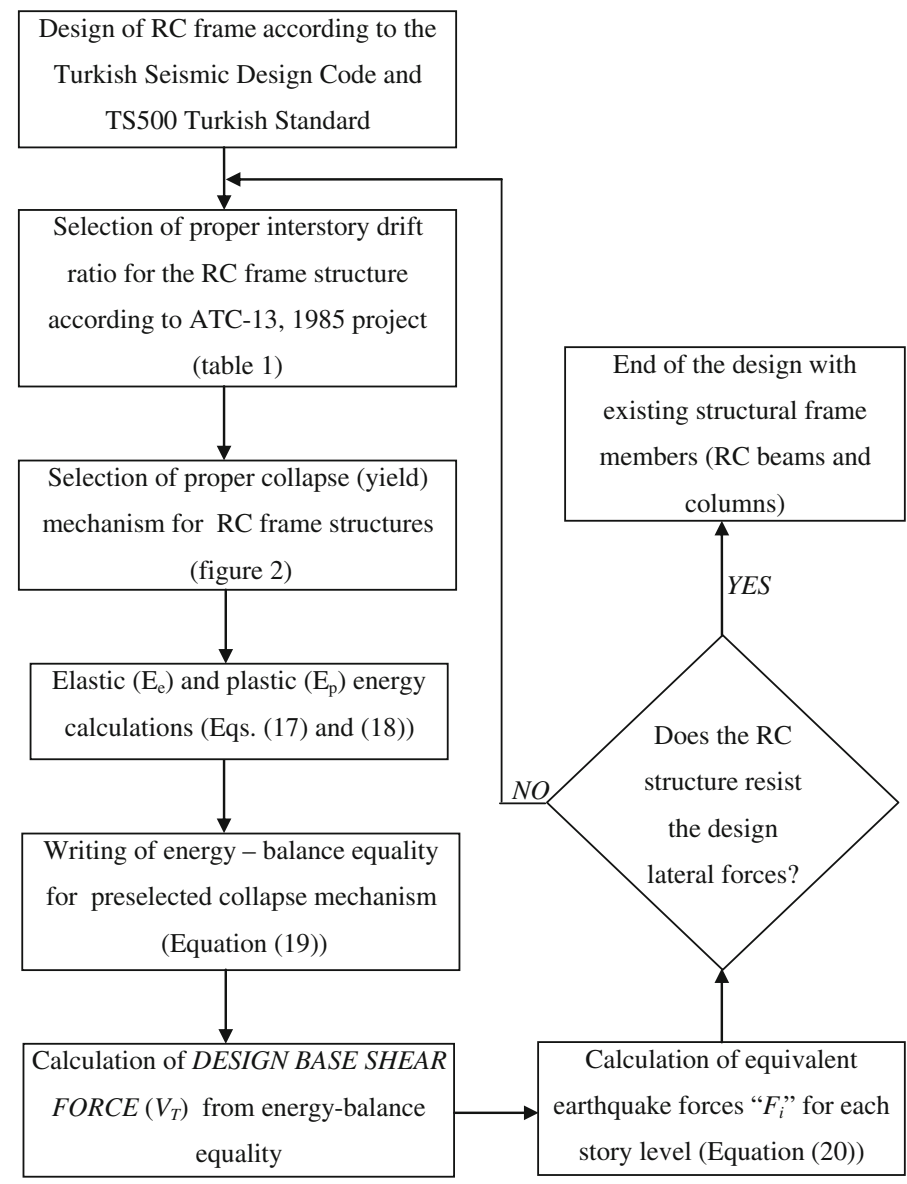

Figure 6. Flow chart of the energy-based design methodology. 

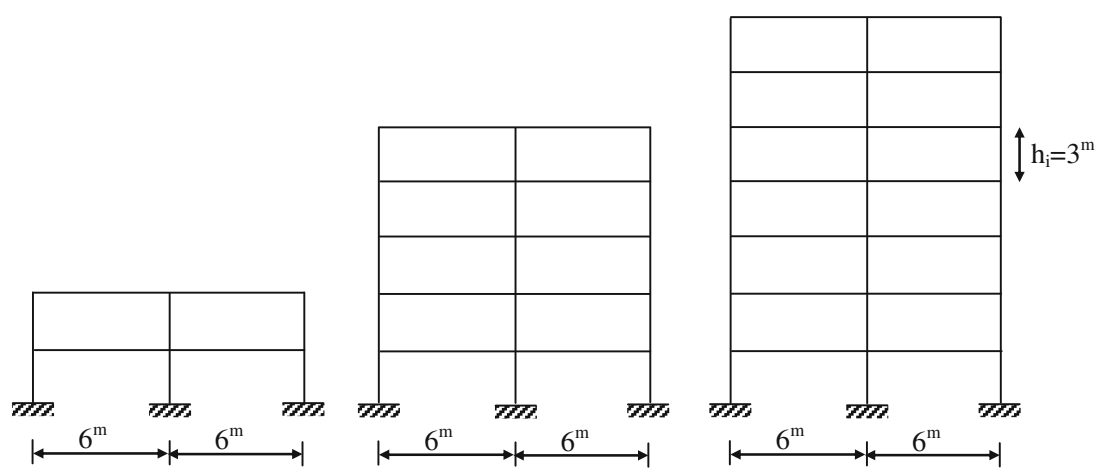

Figure 7. 2, 5 and 7-story RC frame structures.

\& Ozcebe 2001) because of not having high degrees of section ductility, in this study it is investigated to what extent the energy-based limit analysis procedure is convenient for RC structures. $\mathrm{RC}$ sections are designed ductile and RC frames which consist of these ductile sections are investigated if the frames are convenient for the limit state energy-based design. The limit states are described by using the suitable target displacement (interstory drift ratio) for the structure. The flow chart of the iterative design procedure is given in figure 6.

\section{Case study}

2, 5 and 7-story RC frame structures are chosen to apply the energy-based design methodology. Concrete and steel material strengths are $25 \mathrm{MPa}$ and $420 \mathrm{MPa}$, respectively. The frames are regular RC structures with $G=20 \mathrm{kN} / \mathrm{m}$ dead load and $Q=7.5 \mathrm{kN} / \mathrm{m}$ live load in all spans. $\mathrm{RC}$ frames are all first-mode dominated structures. Typical story heights are 3 meters and spans are 6 meters (figure 7). Columns and beams have the same section widths and heights in all story levels. Structures are assumed to be in first-degree earthquake zone and Z3 local soil class TSDC (2007).

Table 2. Energy-based design parameters.

\begin{tabular}{lccc}
\hline & 2-story frame & 5-story frame & 7-story frame \\
\hline$V_{T} / W$ (Energy-based design) & 0.368 & 0.268 & 0.220 \\
$T_{1}(\mathrm{sec}).($ Cracked section) & 0.401 & 0.876 & 1.023 \\
$\theta_{T}=\delta / H(\%)$ & 1.2 & 1.2 & 1.2 \\
Column sections (cm) (TSDC \& TS500 design) & $40 \times 40$ & $40 \times 40$ & $45 \times 45$ \\
Beam sections (cm) (TSDC \& TS500 design) & $30 \times 50$ & $30 \times 50$ & $30 \times 60$ \\
Column sections (cm) (Energy-based design) & $40 \times 40$ & $45 \times 45$ & $50 \times 50$ \\
Beam sections (cm) (Energy-based design) & $30 \times 50$ & $30 \times 50$ & $30 \times 55$ \\
\hline
\end{tabular}




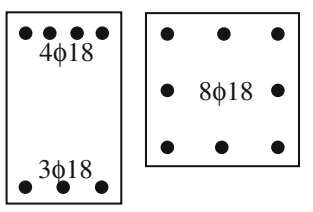

\# 2-story frame \#

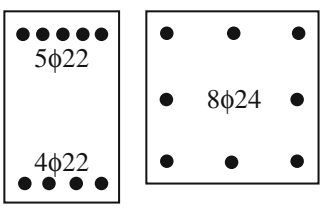

\# 5-story frame \#

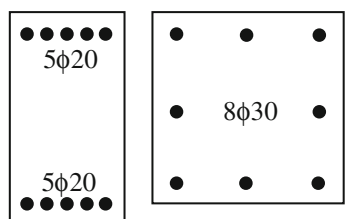

\# 7-story frame \#

Figure 8. Energy-based methodology design results.

In the study, elastic yield rotation $\left(\theta_{y}\right)$ is chosen $1 \%(0.01)$ according to the Priestley's estimation (Priestley et al 2007), (Eq. 12). The total target base rotation of the frames $\left(\theta_{T}\right)$ is taken $1.2 \%(0.012)$ according to ATC-13 (1985) report. This corresponds to the Moderate Damage State and Performance Level IV (ATC-13 1985). Collapse (yield) mechanism is pre-selected as in figure 2. Plastic hinges are assumed to form in the bottom regions of the columns (at the base) and in the beam edges (figure 2). The energy-based design parameters of the structures are given in table 2. In table 2, column and beam sections which are obtained from the existing methodology can be seen with the other design parameters. The result column and beam sections with the reinforcement detailing are given in figure 8.

In the study, RC frames are designed according to the Turkish Seismic Design Code (TSDC 2007) and TS500 (2000) standard at the beginning. The iterative energy-based design begins with these structural members (beams and columns). Then after the last iteration, the $\mathrm{RC}$ sections obtained from the last iteration are accepted as the result of the design. In table 2, beam and column sections obtained from energy-based design are the result dimensions of the structural members.

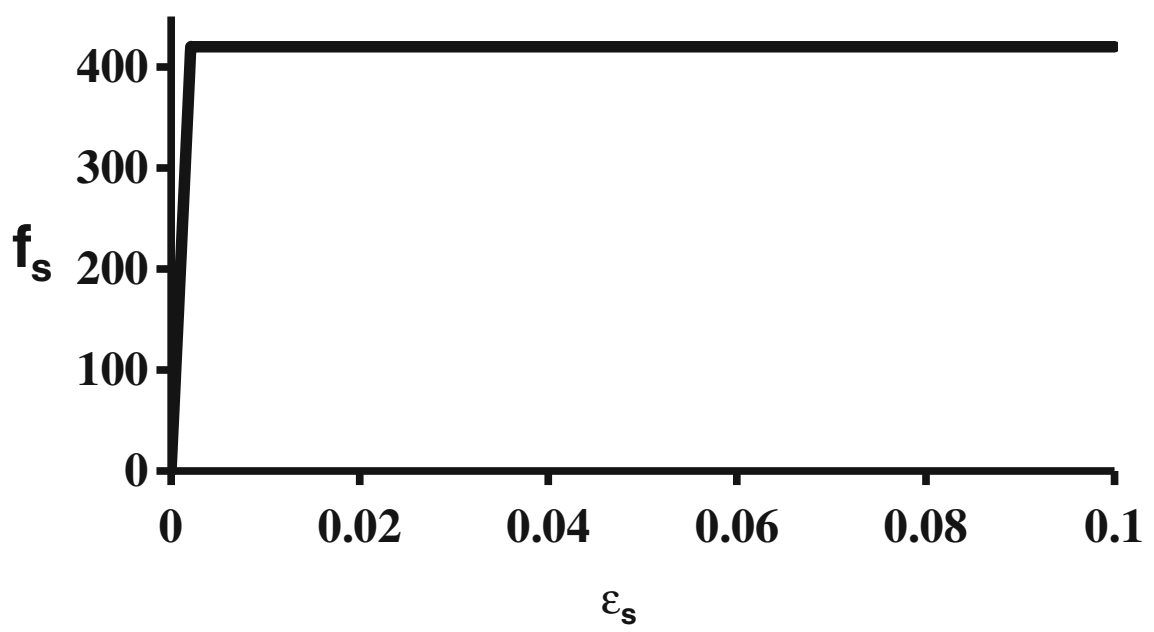

Figure 9. Stress-strain $\left(\mathrm{f}_{s}-\varepsilon_{S}\right)$ curve model of reinforcement steel. 

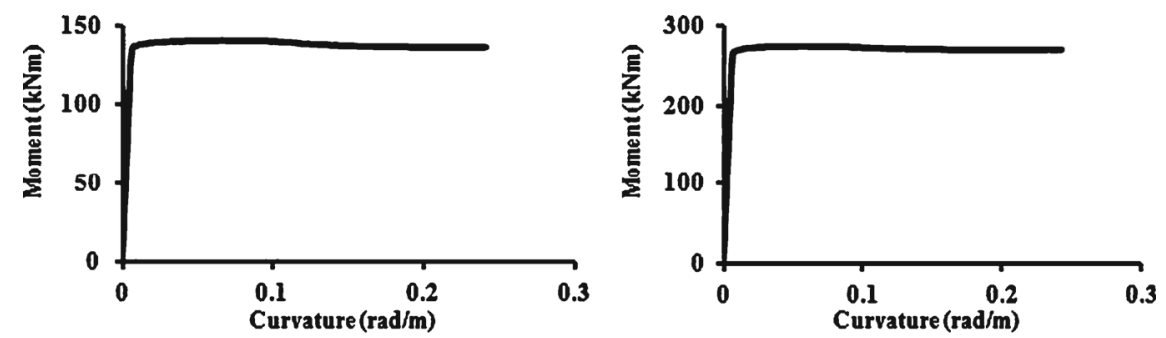

(a)

(b)

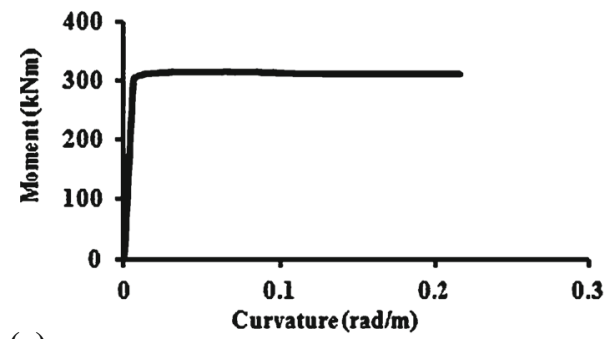

(c)

Figure 10. Positive moment-curvature relation of beams; (a) 2-story frame, (b) 5-story frame, (c) 7-story frame.

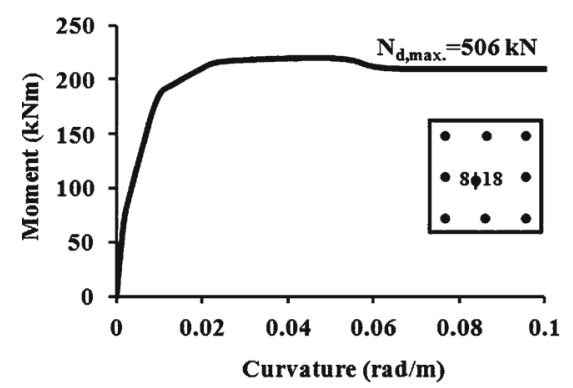

(a)

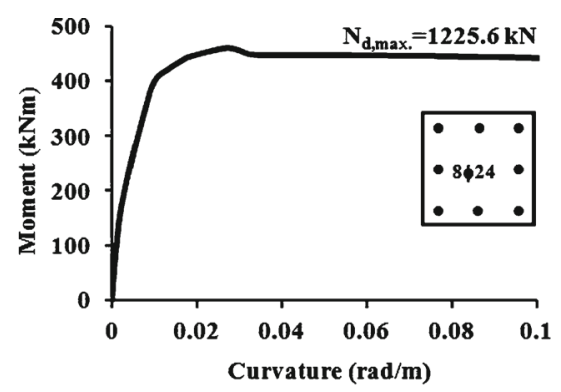

(b)

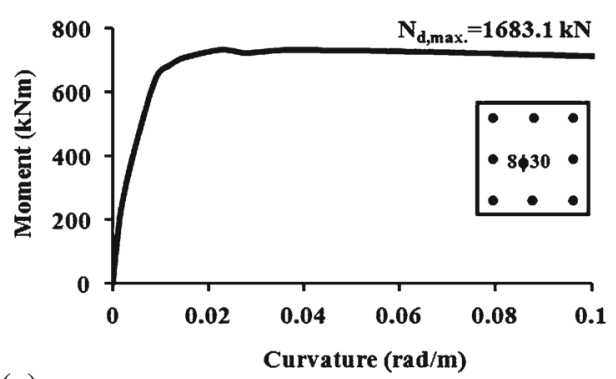

(c)

Figure 11. Moment-curvature relation of columns; (a) 2-story frame, (b) 5-story frame, (c) 7-story frame. 


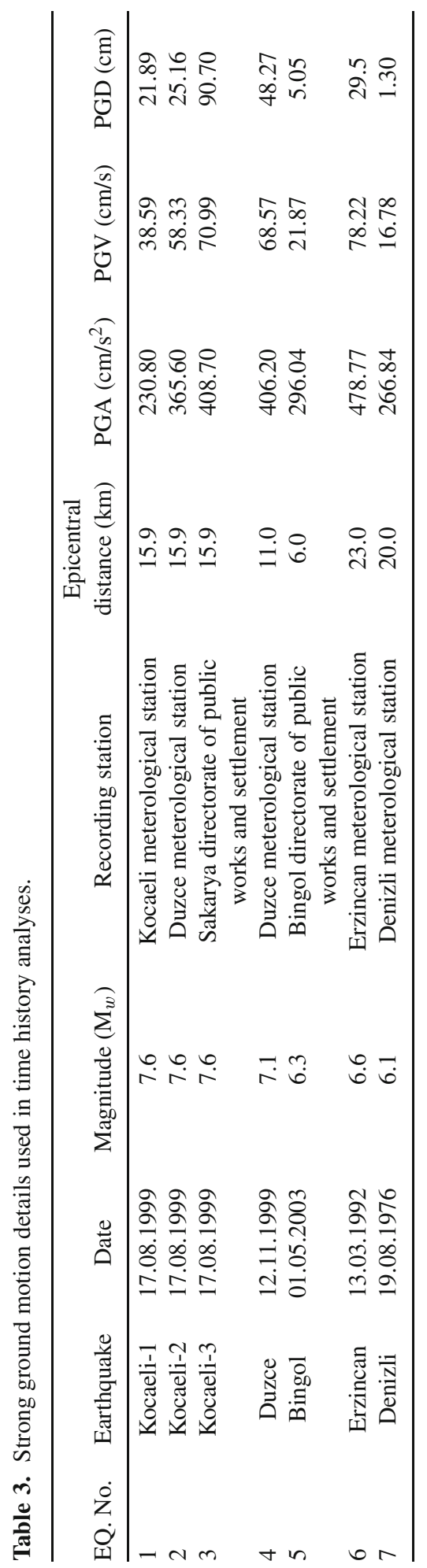




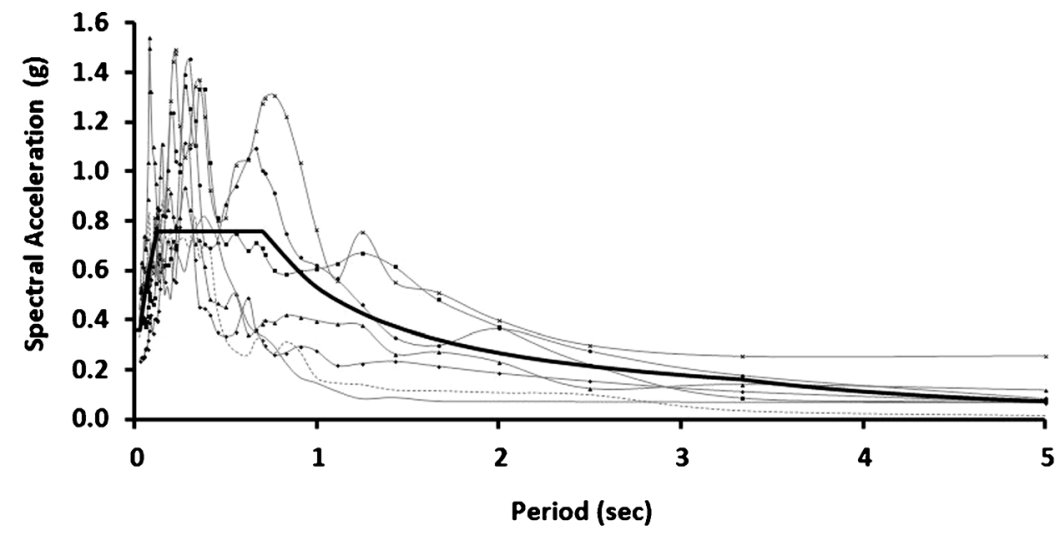

- Kocaeli - - Kocaeli - Kocaeli - Duzce $\cdots$ Bingol $\rightarrow$ Erzincan $—$ Denizli — Mean Spectrum

Figure 12. Mean spectrum and spectra of the ground motion records.

For plastic energy $\left(E_{p}\right)$ calculations within the study, the moment-curvature analyses are performed by using XTRACT (2006), cross section analysis software for structural members (beams and columns). Mander confined and unconfined concrete models are used in the analyses. The stress-strain $\left(\mathrm{f}_{s}-\varepsilon_{s}\right)$ curve of reinforcement steel assumed in the moment-curvature analyses of the study is shown in figure 9. Positive moment-curvature relations of beams of all frames are given in figure 10. In addition, moment-curvature curves of columns obtained for the maximum value of axial loads are shown in figure 11.
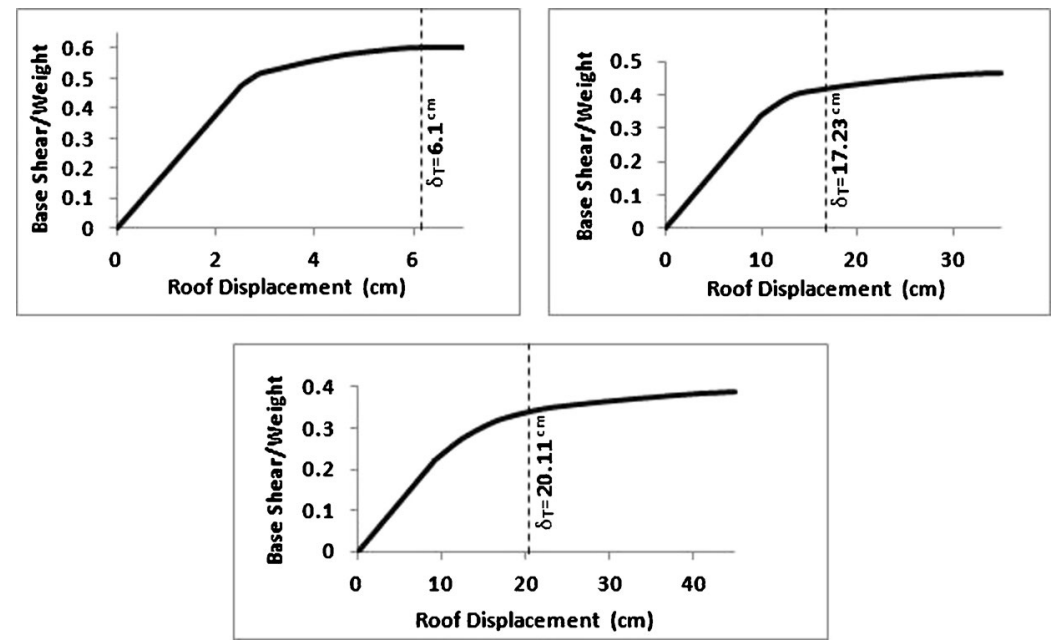

Figure 13. Pushover curves and target displacements of 2, 5 and 7-story RC frame structures. 

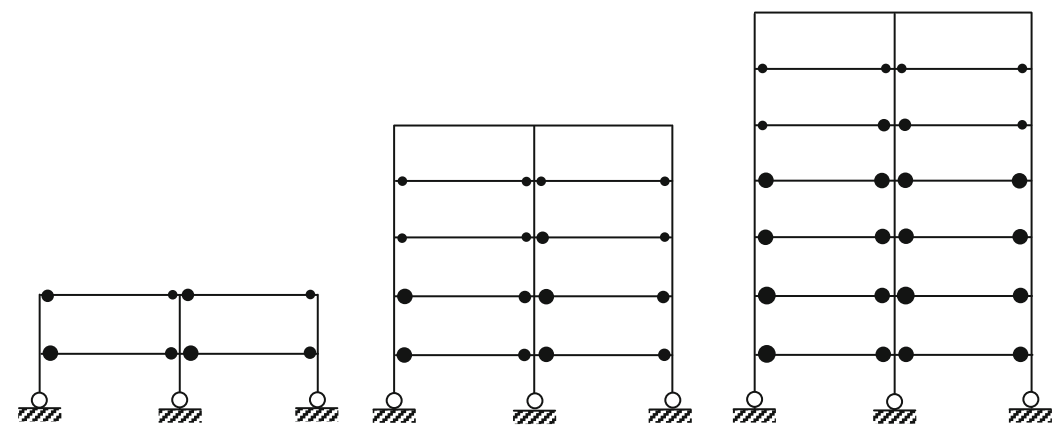

Figure 14. Plastic hinge distribution obtained from pushover analyses.

Moment-curvature relationships of the sections are converted to moment - plastic rotation relationships for nonlinear analyses within the study. In this conversion; the plastic hinge length $\mathrm{L}_{p}$ is taken to be half of the cross section depth due to its simplicity. This approximation is also presented in the TSDC (2007).

Nonlinear static and dynamic analyses are performed by using SAP2000 Nonlinear (2011) and the Direct Integration Method is used in nonlinear dynamic analyses.

In the study, a set of 7 strong ground motions, that were recorded at different soil sites in Turkey and have a magnitude range of 6.1 to 7.6 are chosen for nonlinear time history analyses. The considered earthquakes are the most destructive earthquakes occurred in the historical background of Turkey. As specified in the TSDC (2007), duration of all ground motions is more than five times of the first natural vibration period of the structures and 15 seconds. And also according to TSDC (2007), in case of using recorded seismic ground motions at least three seismic ground motions should be used and in nonlinear analysis, in case of using three ground motions the maximum of results, and in case of using at least seven ground motions average of results shall be taken for the design. Earthquakes are selected considering their fault mechanisms and near fault effects are not taken into account in nonlinear dynamic analyses.

Strong ground motion details used in nonlinear time history analyses are given in table 3 (http://www.deprem.gov.tr). The mean spectrum and spectra of the ground motion records can be seen in figure 12 .

Pushover curves of the frame structures can be seen with target displacement values in the figure 13. Structures are pushed to these target displacement values. The lateral load patterns

\begin{tabular}{cccccc} 
Beam & Column & & Beam & \multicolumn{1}{c}{ Column } \\
\\
- & $\bigcirc$ & $\theta_{p}<0.002$ & $\bullet$ & $\bigcirc$ & $\theta_{p}<0.005$ \\
- & $\bigcirc$ & $0.002<\theta_{p}<0.007$ & - & $\bigcirc$ & $0.005<\theta_{p}<0.01$ \\
& $\bigcirc$ & $0.007<\theta_{p}<0.01$ & $\bigcirc$ & $\bigcirc$ & $0.01<\theta_{p}<0.03$ \\
& $\bigcirc$ & $\theta_{p}>0.01$ & $\bigcirc$ & $\bigcirc$ & $\theta_{p}>0.03$
\end{tabular}

Figure 15. Range of the plastic hinge rotations in figure 14 (Left side is for 2 and 5-story frames and right side is for 7 -story frame). 
used in the pushover analyses are proportional to the first mode of the frames. Plastic regions of the frames are given in figure 14. The range of the plastic hinge rotation values in figure 14 is given in figure 15.

Interstory drift ratios which are obtained from nonlinear static (pushover) and nonlinear dynamic (time history) analyses for 2, 5 and 7-story RC frames are given in figures 16 and 17. From the interstory drift graphs it can be understood that the target displacement is not generally exceeded in the upper story levels (figures 16 and 17). In the study, performance levels (target

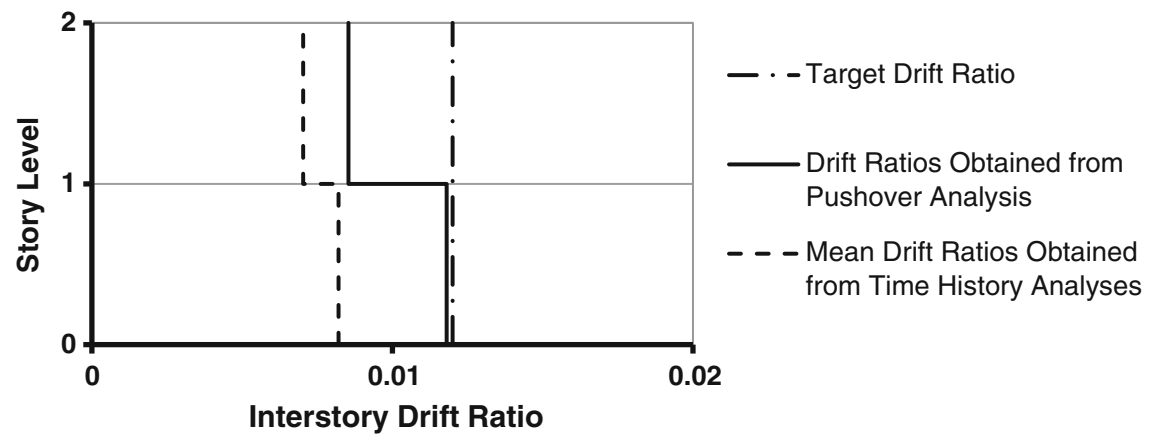

(a)

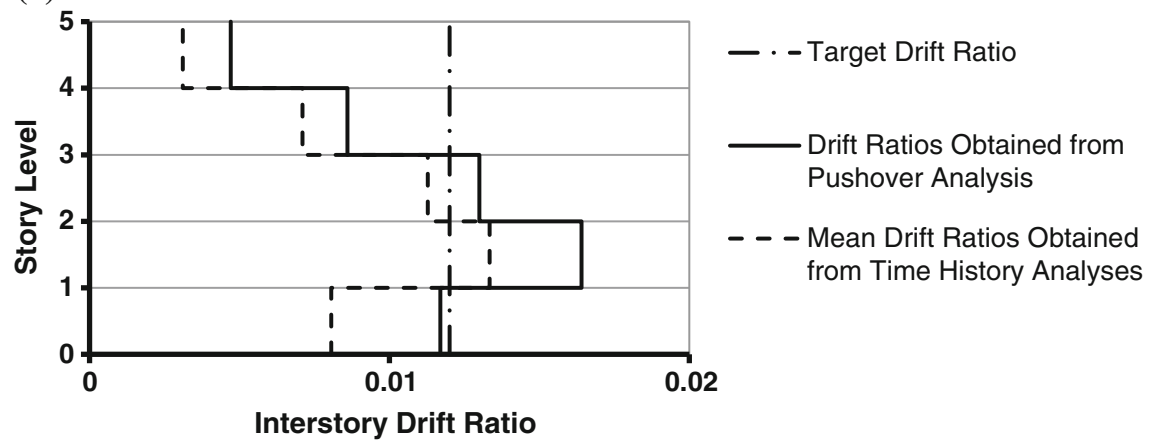

(b)

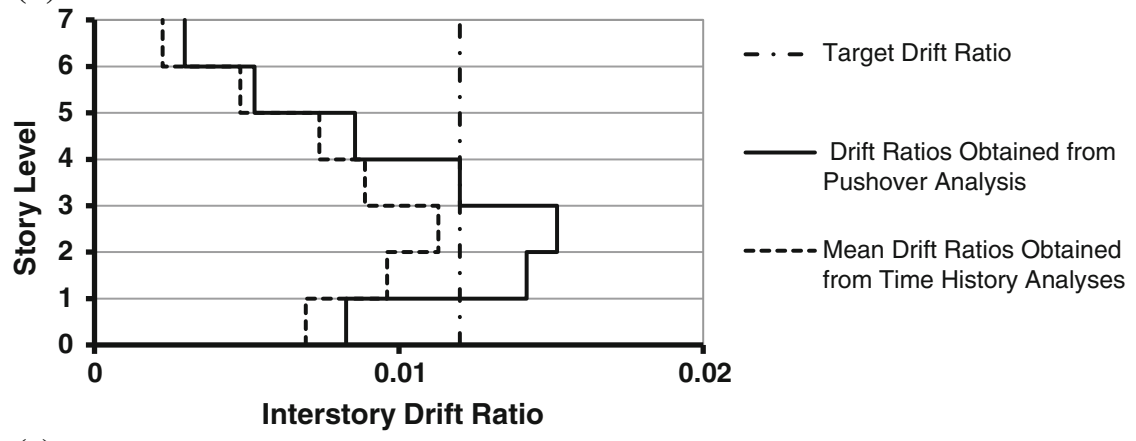

(c)

Figure 16. Target drift and interstory drift ratios obtained from nonlinear analyses; (a) 2-story frame, (b) 5-story frame, (c) 7-story frame. 


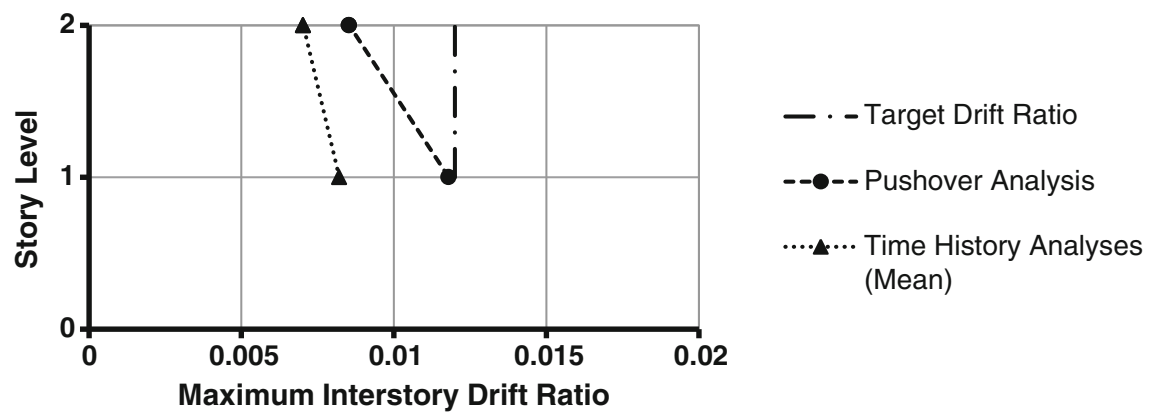

(a)

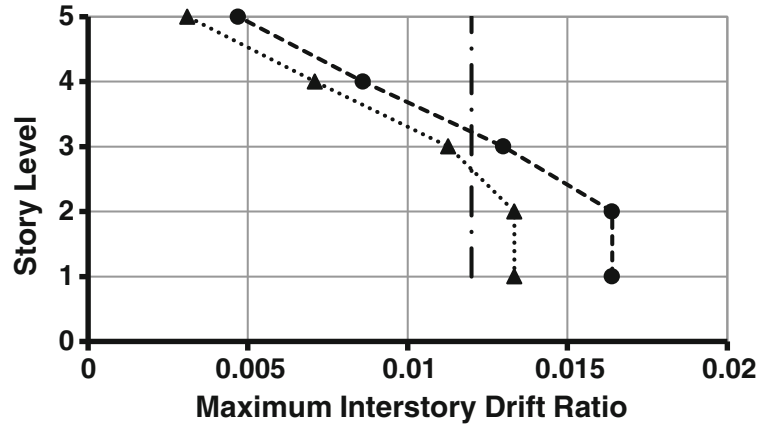

- - - Target Drift Ratio

--๑-- Pushover Analysis

........ Time History Analyses (Mean)

(b)

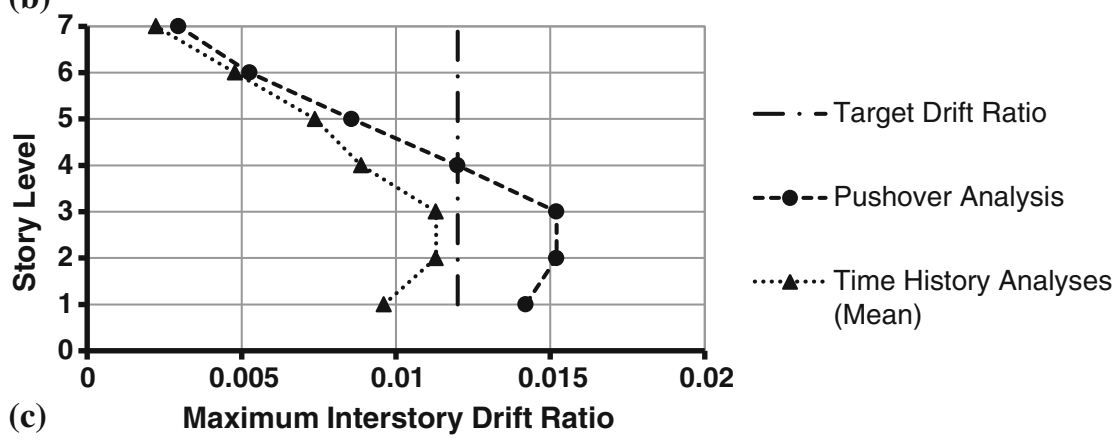

Figure 17. Target drift and maximum interstory drift ratios obtained from nonlinear analyses; (a) 2-story frame, (b) 5-story frame, (c) 7-story frame.

displacements) of the frames are obtained by considering ATC-13 (1985) report and controlled by performing nonlinear static and dynamic analyses.

\section{Conclusions}

In this study, a new energy-based methodology for design of RC frame structures is researched within the study. Frame design is performed by using the total (elastic and plastic) energybalance of structure which is assumed to be in the pre-selected limit collapse state. Performance level (target drift) is pre-selected at the beginning of the design and controlled by performing nonlinear analyses if the structure exceeds the target drift or not. The methodology may be thought as an extension and the Turkish Seismic Design (2007) adaptation of Leelataviwat's 
study (Leelataviwat et al 2002). The difference and originality of the presented methodology is the usage of total energy equality for the design of RC frames.

For targeted moderate damage state (performance level IV) according to ATC-13 (1985) report, the interstory drift results obtained from nonlinear analyses are given in figures 16 and 17. It can be seen from the graphs that the target drift is generally exceeded in the middle story levels. In 5 and 7-story structures, the target drift is exceeded only in the 2nd and 3rd story levels. In the other stories, the target drift is not exceeded according to the results of nonlinear static (pushover) and nonlinear dynamic (time history) analyses (figures 16 and 17). The target drift is not exceeded in all story levels for the 2-story RC frame structure. In figures 16 and 17, the drifts obtained from nonlinear time history analyses are the mean result values of dynamic analyses performed by using seven earthquake records. The energy-based methodology used in this study is also a displacement-based design methodology in one sense because energy - balance equalities of the structures are written for pre-selected target drift (performance level) value. After writing energy - balance equality, the design base shear is obtained and applied to the structures.

The design methodology within the study may not be too convenient for irregular structures. Because; collapse mechanism is estimated at the beginning of design and the designed structures are expected to suit to the pre-selected yield mechanism. In this study, the yield mechanism is assumed to be as in figure 2. Plastic regions of the frames which are obtained by performing nonlinear static analyses can be seen in figure 14. Plastic mechanism of the structures which were pushed up to the performance points is compatible with the pre-selected collapse mechanism. That is why the regular RC frame structures are chosen for the energy-based design.

There are some studies which should be done to improve the presented design methodology. The methodology is improved for only the first-mode dominated regular frame structures. First mode shape of the structure is used in energy-balance equalities within the design. More investigations are required to take the higher mode of the structures in analyses. The performance-based design methodology can be improved by taking different spans and story heights. Elastic yield rotation of the frame is taken $1 \%$ considering Priestley's equation. This yield rotation value can be improved by considering the structural properties and the improved rotation value can be used in the methodology for better results.

\section{Symbols}

$A_{s}$ Area of tension reinforcement of RC beam section.

$A_{s}^{\prime}$ Area of compression reinforcement of RC beam section.

$d$ Distance from the extreme fibre in compression to the centroid of the steel on the tension side of the member.

d' Concrete cover.

$E$ Total energy consumption in ductile RC section.

$E_{e}$ Elastic energy.

$E_{p}$ Plastic energy.

$E_{p b}$ Plastic energy of plastic hinges that occur in beam members.

$E_{p c}$ Plastic energy of plastic hinges that occur in column members.

$E_{p \text {,beam }}$ Plastic energy dissipation value of a plastic hinge that occurs in beam member.

$E_{p, \text { column }}$ Plastic energy dissipation value of a plastic hinge occurs in column member.

$E_{p}^{\prime}$ Plastic energy in unit length of the plastic region.

$F_{i}$ Lateral design loads.

$f_{y d}$ Yield strength of steel reinforcement. 
$H$ Total height of the structure.

$h_{b}$ Height of RC beam.

$H_{i}$ Height of story $I$.

$H_{N}$ Height of story $N$.

$L_{b}$ Beam span.

$L_{p b}$ Plastic hinge length of a beam.

$m$ Beam number in one story.

$M$ Total mass of the system.

$M_{p}$ Plastic moment.

$M_{p b}$ Plastic moment of beam.

$M_{r b}$ Resistance moment of a beam.

$M_{u}$ Ultimate moment.

$M_{y}$ Yield moment.

$M_{w}$ Magnitude of the earthquake.

$n$ Number of stories in the structure.

$V_{T}$ Design base shear force.

$V_{y}$ Yield base shear force.

$\delta_{i}$ Lateral displacements of corresponding story levels.

$\Delta F_{N}$ Additional earthquake load acts on floor $\mathrm{N}$.

$\delta_{p}$ Lateral plastic roof displacement.

$\delta_{y}$ Yield displacement.

$\varepsilon_{y}$ Yield strain.

$\theta_{p}$ Plastic base rotation.

$\theta_{p b}$ Design plastic rotation of beam plastic hinge.

$\theta_{T}$ Total rotaion of structure from the base.

$\theta_{y}$ Elastic yield rotation.

$\phi_{p b}$ Plastic curvature.

$\phi_{p}$ ' Curvature of section in nonlinear behaviour.

$\phi_{y}$ Elastic yield curvature.

$\phi_{u}$ Ultimate curvature.

$\omega_{n}$ Fundamental natural frequency of the system.

\section{References}

Acun B and Sucuoglu H 2007 Structural performance assessment of R/C column members with energybased procedures. Proc. 6th National Conference on Earthquake Engineering; Istanbul Turkey: 85-96 [in Turkish]

Acun B and Sucuoglu H 2010 Performance of R/C columns designed for flexure under severe displacement cycles. ACI Struct. J. 107(3): 364-371

Akbas B 1997 Energy-based earthquake resistant design of steel moment resisting frames. Ph.D. Dissertation. Department of Civil and Architectural Engineering, Illionis Institute of Technology, USA

Akbas B and Shen J 1996 Energy-based earthquake resistant design. Department of Civil and Architectural Engineering, Illinois Institute of Technology; Report No: IIT-CAE-96/005

Akbas B and Shen J 2002 Energy approach in performance-based earthquake resistant design (PB-EQRD). Proc. 12th European Conference on Earthquake Engineering; London, UK, Paper No. 043

Akbas B and Shen J 2003 Earthquake-resistant design and energy concepts. Technical J. Turkish Chamber of Civil Engineers 14(2): 2877-2901 
Akbas B, Shen J and Hao H 2001 Energy approach in performance-based seismic design of steel moment resisting frames for basic safety objective. The Struct. Design of Tall Building 10(3): 193-217

Akbas B, Shen J and Cetiner A N 2002 Energy approach in performance-based earthquake resistant design and determining the reliability of SDOF systems using energy concepts. Research Fund Report, Department of Earthquake and Structural Science, Gebze Institute of Technology; No: Ol-B-02-01-15

Akbas B, Temiz H, Tugsal U M and Gokce F I 2005 Hysteretic energy demands in low, mid and high-rise steel frames. Proc. National Earthquake Symposium; Kocaeli, Turkey: 494-502 [in Turkish]

Akiyama H 1985 Earthquake-resistant limit-state design for buildings. University of Tokyo Press, Japan

ATC-13 1985 Earthquake damage evaluation data for California. Applied Technology Council, ATC-13 Report, Redwood City, California

Eom T S and Park H G 2010 Evaluation of energy dissipation of slender reinforced concrete members and its applications. Eng. Struct, 32(9): 2884-2893

Ersoy U 1998 Moment capacity of reinforced concrete beams and columns. Digest of Technical J. 537-547 Ersoy U and Ozcebe G 2001 Reinforced concrete. Evrim Press, Turkey

Fajfar P, Vidic T and Fischinger M 1989 Seismic design in medium- and long-period structures. Earthquake Eng. Struct. Dynamics. 18(8): 1133-1144

Housner G W 1956 Limit design of structures to resist earthquakes. Proc. 1st World Conference on Earthquake Engineering; Oakland, California, USA: 186-198

International Conference on Building Officials 1997 Uniform building code. Whittier, CA

International Code Council 2003 International building code. Falls Church, VA

Kuwamura H and Galambos T V 1989 Earthquake load for structural reliability. J. Struct. Eng. 115(6): $1446-1462$

Leelataviwat S 1998 Drift and yield mechanism based seismic design and upgrading of steel moment frames. Ph.D. Dissertation. University of Michigan, USA

Leelataviwat S, Goel S C and Stojadinovic B 2002 Energy-based seismic design of structures using yield mechanism and target drift. J. Struct. Eng. 128(8): 1046-1054

Leelataviwat S, Saewon W and Goel S C 2008 An energy-based method for seismic evaluation of structures. Proc 14th World Conference on Earthquake Engineering: Innovation Practice Safety: Bejing, China

Leelataviwat S, Saewon W and Goel S C 2009 Application of energy balance concept in seismic evaluation of structures. J. Struct. Eng. 135(2): 113-121

MacGregor J G 1997 Reinforced concrete: mechanics and design. Prentice Hall, New Jersey, USA

Manfredi G 2001 Evaluation of seismic energy demand. Earthquake Eng. Struct. Dynamics 30(4): 485-499

Park H G and Eom T S 2006 A simplified method for estimating the amount of energy dissipated by flexure dominated reinforced concrete members for moderate cyclic deformations. Earthquake Spectra. 22(3): 459-490

Priestley M J N, Calvi G M and Kowalsky M J 2007 Displacement-based seismic design of structures. IUSS Press, Pavia, Italy

SAP2000 Nonlinear Version 15.0.1 2011 Structural Analysis Program. Computers and Structures Inc., Berkeley CA

Strong Ground Motion Database of Turkey, http://www.deprem.gov.tr

Sucuoglu H and Erberik M A 2004 Energy-based hysteresis and damage models for deteriorating systems. Earthquake Eng. Struct. Dynamics 33(1): 69-88

Turkish Standard Institute TS500 2000 Requirements for Design and Construction of Reinforced Concrete Structures. Ankara, Turkey

Turkish Seismic Design Code 2007 Ministry of Public Works and Settlement, Ankara

Uang C M and Bertero V V 1990 Evaluation of seismic energy in structures. Earthquake Eng. Struct. Dynamics 19(1): 77-90

XTRACT V.3.0.7 (2006). Imbsen Software Systems, Sacramento

Zahrah T F and Hall W J 1984 Earthquake energy absorption in SDOF structures. J. Struct. Eng. ASCE. 110(8): $1757-1772$ 